\title{
The palmomental reflex - overview and clinical significance
}

\author{
Ioan-Cristian Lupescu', Adriana Octaviana Dulamea ${ }^{1,2}$, Daniela Anghel ${ }^{1,2}$ \\ ${ }^{1}$ Neurology Department, Fundeni Clinical Institute, Bucharest, Romania \\ 2"Carol Davila" University of Medicine and Pharmacy, Bucharest, Romania
}

\begin{abstract}
The palmomental reflex is a well-known neurologic sign, however its current diagnostic value is considered limited and its role in the neurologic examination has been questioned. Given that a century has passed since its first description in 1920, we conducted a review of the literature about the palmomental reflex, beginning with its physiology and prevalence in the general population, and continuing with its possible diagnostic and prognostic value in relation to neurologic disorders such as dementia, Parkinson disease, amyotrophic lateral sclerosis, stroke and frontal lobe disease.
\end{abstract}

Keywords: palmomental reflex, primitive reflex, dementia, frontal release sign

\author{
Abbreviations (in alphabetical order) \\ AIDS - acquired immune deficiency syndrome \\ AD - Alzheimer's disease \\ ADL - activities of daily living \\ ALS - amyotrophic lateral sclerosis \\ HIV - human immunodeficiency virus \\ LBD - Lewy body dementia \\ MRI - magnetic resonance imaging \\ PD - Parkinson's disease \\ PMR - palmomental reflex \\ $\mathrm{VP}$ - vascular parkinsonism
}

\section{INTRODUCTION}

The palmomental reflex (PMR) was first described in 1920 by Gheorghe Marinescu and Anghel Radovici, in a patient with amyotrophic lateral sclerosis (ALS) [1,2]. The reflex can be elicited by stroking the thenar eminence with a blunt object, which leads to contraction of the ipsilateral mentalis muscle $[3,4]$.

The pathway of the PMR is thought to be polysynaptic [5]. The sensory innervation of the thenar eminence is provided by first order neurons of the C6 dorsal root ganglia, via the palmar branch of the median nerve [6]. These neurons synapse with intermediate second order neurons, whose axons then ascend in the lateral columns of the spinal cord (as part of the spinothalamic tracts) and give collaterals to the facial nerve nucleus of the pons. The motor neurons of this nucleus innervate the chin muscles via the facial nerve $[1,2]$.

The PMR is included in the group of primitive or "archaic" reflexes, along with the snout, suck and grasp reflexes, since they are normally seen in infants (during the first year of life) [7]. These reflexes can reemerge during adulthood in the setting 
of frontal lobe disease, hence the term frontal release signs [8]. This has been hypothesized to be a release phenomenon of sensorimotor automatisms, which are normally inhibited by the frontal lobe [9].

The PMR has also been noted in lesions of the cortico-nuclear and cortico-spinal tracts $[3,4]$, and even in normal individuals, thus being considered very nonspecific [8].

For this review, we conducted a search on Pubmed using the keywords "palmomental" and "palm-chin" and selected all articles which had abstracts available in English.

\section{PHYSIOLOGIC VERSUS PATHOLOGIC}

The overall incidence of the PMR in healthy adults ranges between 0 and 58\% [10]. It can be encountered in all age groups (often occurring alone), hence some authors consider it a normal phenomenon [11]. It has also been stated that primitive reflexes should be considered abnormal only in the setting of overt cerebral pathology [12].

There are, however, certain features of the PMR which orient towards neurologic disease:

- Instead of simply testing for its occurrence, it is perhaps more relevant to search for responses that are strong, sustained and easily repeatable, and also for mentalis contractions elicited by stimulation of other skin areas than the palm [13].

- Habituation behavior (in the setting of repeated stimulation) is different between healthy subjects and those with neurologic disease [14].

- If present in normal individuals, the PMR is usually symmetrical, whereas an asymmetrical response may be a more reliable indicator for a lesion of the nervous system [15].

- Finally, one study comparing 50 patients with prolonged coma, 50 patients with recent cerebrovascular events and 100 age-matched controls, found that only the presence of at least two primitive reflexes could differentiate between normal and neurological patients [16].

One thing to note is that the inter-rater reliability for PMR detection may be weak, as was shown in a study of 97 patients examined by 2 neurologists in a blind fashion [17].
The PMR was studied electromyographically both in neonates [18] and adults [19], by recording the electrical response of the mentalis muscle after repetitive mechanical stimulation of the thenar eminence. In neonates, PMR potentials showed variability in amplitude and duration, but not in latency, and were present bilaterally in almost all subjects. In adults, PMR potentials showed variability in amplitude, duration and latency, and were obtained even when the PMR was not clinically apparent.

Variants of this reflex have been described over the time, such as the thumb-chin reflex [20,21], palmo-cervical reflex [22] and palmo-levator labii superioris reflex [5]. A planto-mental reflex has also been identified by electromyographic stimulation of the plantar skin, but only in subjects with focal or diffuse brain injury [23].

\section{RELATION WITH AGING}

The prevalence of the PMR follows a "U-shaped" curve during lifetime: initially, the reflex is present in almost all infants; its occurrence decreases during early adulthood and then increases in persons over 65 years old. Thus, the frequency of the PMR is highest during the developing and aging stages of the nervous system [24].

Other authors established that its incidence rises progressively after the age of 20 years, with about $10 \%$ per decade [15].

It is unclear if the PMR and other primitive reflexes are associated with cognitive decline, as different studies have given conflicting results:

- The PMR, glabellar tap and snout reflex were exhibited by approximately 33\% of 1241 healthy adults (aged 45-91 years-old). Their frequency increased with age and their presence was associated both with worse performance on cognitive tests, and with brain MRI changes (white matter hyperintensities, lacunar infarcts, caudate nuclei atrophy and global brain atrophy) [25].

- In another study, the PMR, glabellar tap and snout reflex were elicited by half of 68 normal aged individuals and their presence correlated with incidental findings on brain MRI, but not with brain atrophy or cognitive decline [26].

- Finally, in a study of 470 patients aged 25-82 years-old, the primitive reflexes did not cor- 
relate with cognitive decline neither at baseline, nor at 3- and 6-years follow-up. They did however increase in frequency with age [27].

In another train of thoughts, presence of the PMR was identified as a potential predisposing factor for falling, based on a prospective 1-year study of 336 elderly persons [28].

\section{RELATION WITH DEMENTIA}

Whether or not primitive reflexes have a role in diagnosing dementia is debatable. Demented patients do seem to exhibit multiple primitive reflexes, which is understandable:

- In a study involving 128 elderly patients living in retirement facilities, the coexistence of three primitive reflexes (palmomental, glabellar tap and snout) was consistently associated with dementia [29].

- Likewise, in another study, the occurrence of more than two primitive reflexes was not seen in elderly controls but was noted in cerebrovascular patients and especially in those with vascular dementia, having 93\% specificity (however with low sensitivity) [30].

But do primitive reflexes have any additional clinical or prognostic value? In an analysis of 136 cases of Alzheimer's disease (AD), no differences regarding duration of dementia or cognitive decline were noted between those with primitive reflexes (including the PMR) and those without. Patients exhibiting primitive reflexes did have greater functional limitations (as measured by the ADL scale) and a higher incidence of gait disturbance, rigidity and apraxia [31].

The PMR was also proposed as an early sign of $A D$ in persons under 80 years old. The PMR was more frequent in AD patients compared with agematched controls, both 2 years before diagnosis ( $25 \%$ versus $7 \%$ ), and at the time of diagnosis $(30.3 \%$ versus $12.3 \%)$. This may be related to early amyloid deposition in the frontal lobes [32].

In patients who suffered traumatic brain injury, the occurrence of primitive reflexes and paratonia may help predict the degree of cognitive impairment and functional independence [33].

Although termed "frontal release signs", according to one study, primitive reflexes were not predictive of frontally based dementias (frontotemporal dementia and vascular dementia), being more prevalent in Lewy Body Dementia and in Alzheimer type dementia [34].

\section{RELATION WITH ALS}

As mentioned above, the PMR was described for the first time in a person with ALS and is a common occurrence in this group of patients, especially in those with bulbar onset. This is easily explained by (a) its integration in the brainstem and (b) its release secondary to cortico-bulbar tract dysfunction. In one study, the frequency of the PMR in non-demented ALS patients was $46 \%$, significantly greater than that seen in non-demented patients with other neurological disorders $(29 \%)$ or in healthy individuals (16\%) [35].

Apart from its frequency, the PMR may also have prognostic value in ALS since its presence is associated, as mentioned, with higher rates of bulbar involvement and upper limb involvement [36].

Other primitive reflexes are also seen in ALS, especially the corneomandibular reflex and glabellar tap. Patients with 3 or more primitive reflexes appear to have greater cognitive decline, as measured in one study by the Frontal Assessment Battery and Weigl's Sorting Test [37].

\section{RELATION WITH STROKE}

It is known that the PMR has a high incidence in patients with vascular hemiplegia [38], however, during the first few weeks of acute ischemic stroke, it tends to be absent on the affected side, as was shown in a Romanian study comprising 71 patients [39].

\section{RELATION WITH PARKINSON'S DISEASE AND RELATED DISORDERS}

Primitive reflexes are prevalent in Parkinson's disease (PD) with or without dementia, especially the PMR and glabellar tap [40]. The occurrence of these reflexes does not correlate with plasma dopamine levels, however the PMR and corneomandibular reflex are more likely to be encountered in patients with advanced disease [41].

By comparing 109 parkinsonian patients with 356 normal subjects, a much higher prevalence of 
the PMR $(71.5 \%)$ was noted in the parkinsonian group, as opposed to only $16.3 \%$ in the control group. There was a positive correlation between presence and intensity of the PMR on one hand, and degree of akinesia on the other [42].

There may also be a role for the PMR and snout reflex in differentiating between $P D$ and vascular parkinsonism (VP). In one study comparing 132 PD patients with 55 VP patients, the snout and palmomental reflexes were more prevalent in the VP group, with $82 \%$ specificity and $84 \%$ sensitivity [43].

During neuroleptic treatment, the primitive reflexes can become exaggerated, as was shown in a study of 14 psychotic patients with organic brain damage treated with Haloperidol. The authors interpreted this as a "decompensation phenomenon" induced by blockage of dopamine receptors in the brain [44].

As mentioned above, primitive reflexes are also frequent in Lewy Body Dementia, and in fact the coexistence of at least two primitive reflexes has been more frequently seen in LBD than in other parkinsonian syndromes [45].

\section{RELATION WITH FRONTAL LOBE LESIONS}

Since they are termed "frontal release signs", one would expect to elicit PMR and other primitive reflexes in the setting of frontal lobe lesions. However, this was not the case in one study involving 226 patients who underwent brain MRI for suspicion of intracranial lesions. Occurrence of the PMR was associated indeed with a high specificity (93\%), but with a low sensitivity $(19 \%)$, indicating that a large proportion of patients with frontal lobe lesions had negative PMRs [46].

The PMR and snout reflex were noted temporary in a patient with catatonic schizophrenia, perhaps because of transient frontal lobe dysfunction [47].

\section{RELATION WITH HEAD AND NECK PAIN}

A Russian study revealed a statistically significant prevalence of the palmomental reflex in $p a$ tients with cervicalgia and migraine (86.4\%), com- pared to patients with cervicalgia accompanied by tension-type headache and/or cervicogenic headache (7\%) [48].

\section{RELATION WITH OTHER DISORDERS}

A higher prevalence of the PMR was found in HIV-1 positive patients, as compared with HIV-1 negative drug abusers and with healthy subjects. Additionally, the snout reflex and/or glabellar tap could also be elicited in the seropositive group along with the PMR, but not in the other two groups [49]. The occurrence of the PMR is also higher in those with terminal AIDS than in asymptomatic HIV-positive patients [50].

The PMR seems to be have a low frequency in patients with diabetes mellitus without cerebrovascular disease. This is possibly due to microvascular lesions involving the perforating pontine arteries [51]. Given that the integrating center of the PMR is in the pons, an ischemic lesion at that level could lead to abolition of the reflex.

A greater likelihood for development of postoperative delirium was noted in patients who presented with more than one primitive reflex preoperatively or postoperatively [52].

Finally, one study showed a significantly increased frequency of the PMR in persons with Down syndrome $(47 \%)$ compared with controls (7\%), however its presence did not correlate with the level of mental retardation [53].

\section{CONCLUSIONS}

The palmomental reflex may occur in both healthy subjects and neurological patients. Although it is not "per se" pathological, it may have some diagnostic and prognostic value in certain settings (association with brain MRI findings in the elderly, possible early clinical sign of $\mathrm{AD}$, association with bulbar and upper limb involvement in ALS, occurrence with frontal lobe disease, high prevalence in parkinsonian patients).

Despite its low sensitivity and specificity, its presence (especially with other primitive reflexes), may help refine the clinical diagnosis.

Conflict of interest: none declared Financial support: none declared 


\section{REFERENCES}

1. Marinesco G, Radovici A. Sur un reflexe cutane nouveau: reflexe palmo-mentonnier. Rev Neurol 1920;27:237-240.

2. Fine EJ, Darkhabani MZ. Chap. 16 History of the development of the neurological examination. In: Finger S, Boller F, Tyler KL. Handbook of Clinical Neurology. History of Neurology. Elsevier. 2010:225.

3. Câmpeanu E. Examenul neurologic. In: Câmpeanu E, Argintaru D, Lakatos A, Mareș V, Șerban M. Neurologie Clinică I. Editura Dacia Cluj-Napoca, 1979:57.

4. Nica S, Davidescu I. Cap. III Examinarea motilității reflexe. 3.4 Reflexe patologice. In: Nica S, Davidescu I. Neurologie volumul 1. Examinarea neurologică. Editura Universitară "Carol Davila", București, 2007:62-63.

5. Sawhney I, Lekhra OP, Gupta P. Reappraisal of palmomental reflex and its variants. Neurol India. 1995;43(2):101-103.

6. Gilroy AM, MacPherson BR, Ross LM. Upper Limb Neurovasculature. In: Gilroy AM, MacPherson BR, Ross LM. Atlas of Anatomy. Thieme Medical Publishers, Inc. New York. 2008:328-330.

7. Walker HK. The Suck, Snout, Palmomental, and Grasp Reflexes. In: Walker HK, Hall WD, Hurst JW, editors. Clinical Methods: The History, Physical, and Laboratory Examinations. 3rd edition. Boston: Butterworths; 1990. Chapter 71.

8. Blumenfeld H. Chap. 3 The Neurologic Exam as a Lesson in Neuroanatomy. Reflexes. In: Neuroanatomy through Clinical Cases. Sinauer Associates Inc. Sunderland, Massachusetts. 2002:67.

9. Allan HR, Martin AS, Joshua PK, Sashank P. Neurologic Disorders Caused by Lesions in Specific Parts of the Cerebrum. In: Allan HR, Martin AS, Joshua PK, Sashank P. Adams and Victor's Principles of Neurology - 11th Edition. McGraw-Hill Educational, 2019:478-481.

10. Blake JR Jr, Kunkle EC. The palmomental reflex; a physiological and clinical analysis. AMA Arch Neurol Psychiatry. 1951;65(3):337-345.

11. Jacobs $L$, Gossman MD. Three primitive reflexes in normal adults. Neurology. 1980;30(2):184-188.

12. Moretti G, Rizzi C, D'Ambrosio E, et al. [Comparative study of the frequency of 6 primitive reflexes in a hospitalized population of aged patients]. Acta Biomed Ateneo Parmense. 1981;52(5):217-224.

13. Owen G, Mulley GP. The palmomental reflex: a useful clinical sign? J Neurol Neurosurg Psychiatry. 2002;73(2):113-115.

14. Marti-Vilalta JL, Graus F. The palmomental reflex. Clinical study of 300 cases. Eur Neurol. 1984;23(1):12-16.

15. Marx P, Reschop J. The clinical value of the palmomental reflex. Neurosurg Rev. 1980;3(3):173-177.

16. Isakov $E$, Sazbon $L$, Costeff $H$, et al. The diagnostic value of three common primitive reflexes. Eur Neurol. 1984;23(1):17-21.

17. Plutino $A$, Baldinelli $S$, Fiori $C$, et al. Inter-rater reliability of primitive signs in dementia. Clin Neurol Neurosurg. 2019;187:105555.

18. Caccia MR, Osio M, Tornaghi R, et al. Electrophysiological observations on the palmomental reflex in normal neonates. Neurophysiol Clin. 1990;20(6):455-462.

19. Caccia MR, Osio M, Mangoni A. The palmomental reflex from mechanical stimulation in normal man: normative data. Electromyogr Clin Neurophysiol. 1991;31(3):151-156.

20. Brakha S. [Thumb-chin reflex (a modification of the palm-chin reflex)]. Rev Neurol. (Paris). 1956;95(5):429-430.

21. Abe K, Ikawa G. The pollicomental reflex (Bracha's modification of the palmomental reflex), a useful sign in cerebral lesions. Folia Psychiatr Neurol Jpn. 1962;16:80-89.

22. Chansakul C, Teleb M, Bomprezzi R. Palmocervical reflex: a hyperactive palmomental reflex? Neurology. 2010;74(1):91.

23. Domzal T, Chmielewski H. [Electromyographic studies of plantarmental reflex]. Neurol Neurochir Pol. 1975;9(1):37-39.

24. Yu XH, Yang ZJ, Wu FD, et al. [Study on "Hegu (LI 4) regulates face and mouth" based on palmomental reflex]. Zhongguo Zhen Jiu. 2014;34(10):1037-1039.

25. Camarda C, Torelli P, Pipia C, et al. Nociceptive Primitive Reflexes in Neurologically and Cognitively Healthy Aging Subjects. Can J Neurol Sci. 2019;46(2):199-208.
26. Kobayashi S, Yamaguchi S, Okada K, et al. Primitive reflexes and MRI findings, cerebral blood flow in normal elderly. Gerontology. 1990;36(4):199-205.

27. van Boxtel MP, Bosma $\mathrm{H}$, Jolles $\mathrm{J}$, et al. Prevalence of primitive reflexes and the relationship with cognitive change in healthy adults: a report from the Maastricht Aging Study. J Neurol. 2006;253(7):935941.

28. Tinetti ME, Speechley M, Ginter SF. Risk factors for falls among elderly persons living in the community. $N$ Engl $\mathrm{J}$ Med. 1988;319(26):1701-1707.

29. Sinisi L, De Michele G, Mansi D, et al. Relationship of neurological and psychological signs to physical and metabolic risk factors in elderly persons living in retirement facilities: a multidisciplinary approach. Funct Neurol. 1989;4(3):277-282.

30. Di Legge S, Di Piero V, Altieri M, et al. Usefulness of primitive reflexes in demented and non-demented cerebrovascular patients in daily clinical practice. Eur Neurol. 2001;45(2):104-110.

31. Molloy DW, Clarnette RM, Mcllroy WE, et al. Clinical significance of primitive reflexes in Alzheimer's disease. J Am Geriatr Soc. 1991;39(12):1160-1163.

32. Gabelle A, Gutierrez LA, Dartigues JF, et al. Palmomental Reflex a Relevant Sign in Early Alzheimer's Disease Diagnosis? J Alzheimers Dis. 2016;49(4):1135-1141.

33. Wortzel HS, Frey KL, Anderson CA, et al. Subtle neurological signs predict the severity of subacute cognitive and functional impairments after traumatic brain injury. J Neuropsychiatry Clin Neurosci. 2009;21(4):463-466.

34. Links KA, Merims D, Binns MA, et al. Prevalence of primitive reflexes and Parkinsonian signs in dementia. Can J Neurol Sci. 2010;37(5):601-607.

35. Taiello AC, Spataro R, La Bella V. The Primitive Palmomental Reflex in Amyotrophic Lateral Sclerosis. Eur Neurol. 2018;79(3-4):187-191.

36. Arwas N, Leshno A, Gotkine M. The palmomental reflex predicts earlier corticobulbar involvement in ALS. Amyotroph Lateral Scler Frontotemporal Degener. 2018;19(7-8):513-515.

37. Tremolizzo L, Susani E, Lunetta C, et al. Primitive reflexes in amyotrophic lateral sclerosis: prevalence and correlates. $J$ Neurol. 2014;261(6):1196-1202.

38. Demeurisse G, Demol O, Ganty C. Semiological value of the palmo-mental reflex in vascular hemiplegia. Eur Neurol. 1979;18(1):66-72.

39. Tufănoiu E. Palm-chin reflex in acute ischaemic stroke. Rom J Neurol Psychiatry. 1991;29(3-4):149-151.

40. Marterer-Travniczek A, Danielczyk W, Müller F, et al. Release signs in Parkinson's disease with and without dementia. J Neural Transm Park Dis Dement Sect. 1992;4(3):207-212.

41. Huber SJ, Paulson GW. Influence of dopamine and disease severity on primitive reflexes in Parkinson's disease. Eur Neurol. 1989;29(3):141-144.

42. Maertens de Noordhout A, Delwaide PJ. The palmomental reflex in Parkinson's disease. Comparisons with normal subjects and clinical relevance. Arch Neurol. 1988;45(4):425-427.

43. Okuda B, Kawabata K, Tachibana H, et al. Primitive reflexes distinguish vascular parkinsonism from Parkinson's disease. Clin Neurol Neurosurg. 2008;110(6):562-565.

44. Schilkrut R, Rüther $E$, Ackenheil M, et al. Clinical and biochemical parameters during neuroleptic treatment. III. Primitive reflexes during neuroleptic treatment. Pharmakopsychiatr Neuropsychopharmakol. 1976;9(1):43-47

45. Borroni B, Broli M, Costanzi C, et al. Primitive reflex evaluation in the clinical assessment of extrapyramidal syndromes. Eur J Neurol. 2006;13(9):1026-1028.

46. Ladino LD, Isaza S, Delgado J, et al. Diagnostic yield of the palmomental reflex in patients with suspected frontal lesion. $J$ Neurol Sci. 2015;359(1-2):156-160. 
47. Damodaran SS, Sinha VK. Transient release reflexes in catonic schizophrenia. Indian J Psychiatry. 1994;36(3):145-146.

48. Bakhtadze MA, Bolotov DA, Kuzminov KO, et al. [The prevalence of the palmo-mental reflex in patients with cervicocranialgia]. Zh Nevrol Psikhiatr Im S S Korsakova. 2018;118(8):18-22.

49. Orefice G, Carrieri PB, Troisi E, et al. Three primitive reflexes in HIV-1-infected individuals: a possible clinical marker of early central nervous system involvement. Acta Neurol. (Napoli). 1993; 15(6):409-415.

50. Howlett WP, Nkya WM, Kvále G, et al. The snout and palmomental reflexes in HIV disease in Tanzania. Acta Neurol Scand. 1995;91(6):470-476
51. Volpe G, Della Rocca G, Brescia Morra V, et al. Effect of diabetes on some primitive reflexes. Eur J Neurol. 2000;7(4):401-404.

52. Nicolson SE, Chabon B, Larsen KA, et al. Primitive reflexes associated with delirium: a prospective trial. Psychosomatics. 2011;52(6):507-512.

53. Sand T, Mellgren SI, Hestnes A. Primitive reflexes in Down's syndrome. J Ment Defic Res. 1983;27(Pt 1):39-44. 